\title{
Editorial
}

\section{Write of reply?}

"There are three rules for writing the novel. Unfortunately, no one knows what they are."

(W. Somerset Maugham 1874-1965)

In this issue of Acta Neuropsychiatrica that celebrates 1 year since its re-launch I am writing to thank the many authors who have contributed to the success of the journal over the past 12 months. Further, I would like to urge readers to correspond and write to the journal so as to engage their scholarly colleagues in discussion and debate. The Comment \& Critique column of the journal is designed to be a 'broad church' that allows authors to express their views freely either directly in relation to articles that have been published in the journal or on related topics of interest to its readership. This is an important part of publishing in science and indeed in academia as a whole, as it permits further open scrutiny of findings beyond that of peer review and allows ideas to be cogitated and developed more thoroughly. At present we have no limit on the number of comments or critiques we will publish as we are governed solely by salience. For longer opinion pieces or contemporary commentary the journal accepts Editorials and ideally, these should debate a lively issue that pertains to some aspect of current neuropsychiatric practice. To gauge the degree of interest and ascertain whether a topic is novel, authors are advised to send a brief outline of any such proposed editorial to either the Editor-in-Chief or Associate Editor. This also avoids potential overlap and on occasion may allow an editorial to be published alongside other relevant articles. If, however, your proposed piece corresponds best to a special section such as Brain Bytes or Pictures \& Prose then these too can be submitted to the journal and will be considered for publication as part of these series. Again a pre-emptory inquiry directed at the section editor so as to determine suitability is advisable. The editorial office is also happy to field ideas and arrange a suitable marriage of pictures and prose. In this regard I am especially grateful to Professor Keshavan who allowed his artistic skills to be displayed in two issues of the journal last year $(1,2)$ and in so doing facilitated some important and interesting story telling. In 2008 I look forward to further stories of note and hope that you will be encouraged to contribute to the journal and retain your right of reply.

Professor Gin S. Malhi ${ }^{1,2,3}$

${ }^{1}$ Academic Discipline of Psychological Medicine, Northern Clinical School, University of Sydney, Sydney, Australia;

${ }^{2}$ CADE Clinic, Department of Psychiatry, Royal North Shore Hospital, Sydney, Australia; and ${ }^{3}$ Advanced Research and Clinical High-field Imaging (ARCHI), Northern Clinical School, University of Sydney, Sydney, Australia

\section{References}

1. Malhi GS, Keshavan M. Biology and psychology to psychobiology. Acta Neuropsychiatrica 2007;19:211-212.

2. Malhi GS, Allwang C, Keshavan M. Kahlbaum's katatonie and Hecker's hebephrenia. Acta Neuropsychiatrica 2007; 19:314-315. 